\title{
Bonding Strength of Resin Cement to Silicate Glass Ceramics for Dental CAD/CAM Systems is Enhanced by Combination Treatment of the Bonding Surface
}

\author{
Yusuke SHIMAKURA ${ }^{1}$, Yasuhiro HOTTA², Akihiro FUJISHIMA², Jun KUNII², Takashi MIYAZAKI ${ }^{2}$ and \\ Tadaharu KAWAWA ${ }^{1}$ \\ ${ }^{1}$ Department of Prosthodontics, Showa University School of Dentistry, 2-1-1, Kitasenzoku, Ohta-ku, Tokyo 145-8515, Japan \\ ${ }^{2}$ Department of Oral Biomaterials and Technology, Showa University School of Dentistry, 1-5-8, Hatanodai, Shinagawa-ku, \\ Tokyo 142-8555, Japan \\ Corresponding author, Yasuhiro HOTTA; E-mail: hotta@dent.showa-u.ac.jp
}

Received February 10, 2007/Accepted May 7, 2007

\begin{abstract}
To increase the bond strength of CAD/CAM-fabricated, leucite-reinforced glass ceramics with a resin cement, the effects of the following were investigated: surface modification by tribochemical (TBC) treatment, followed by combined application of a silane coupling agent and a functional monomer as a primer. Bond strength was evaluated by a shear bond test. It was found that a silane coupling agent was useful for all the surfaces, particularly for the TBC-treated surface. This was because of the presence of a silica layer on the modified surface. The combination of a silane coupling agent and a functional monomer on the TBC surface allowed marked improvement in bonding, whereby the bonding endured 20,000 cycles of thermal cycling. Therefore, TBC treatment in combination with a silane coupling agent and a functional monomer as a primer substantially increased the bond strength of CAD/CAM-fabricated glass ceramics with resin cement, if the treatment conditions were appropriate.
\end{abstract}

Keywords: Glass ceramics, Shear bond strength, Surface modification

\section{INTRODUCTION}

Due to demand for esthetic crown and bridge restorations by patients, the use of ceramics in place of dental alloys has recently increased ${ }^{1-4)}$. In particular, all-ceramic crown-bridges, without using metal, have come into widespread use. This is chiefly due to the introduction of new materials and processing technologies, such as dental CAD/CAM systems. In the fabrication of all-ceramic crowns by CAD/CAM systems, the restorations are milled directly from machinable ceramic blocks without air bubbles, in a highly precise manner-8. ${ }^{5.8)}$ Since these ceramics are basically brittle, long-term clinical success of allceramic CAD/CAM restorations has so far been based on adhesive cementation ${ }^{9)}$. Thus, various adhesive resin cements have appeared in place of conventional types of dental cement, and this implies substantial improvement in the bonding of allceramic crowns ${ }^{10-13)}$.

However, the inner surface of a crown fabricated by the current CAD/CAM systems, which is the bonding surface for an all-ceramic crown, is relatively smooth. This is a result of milling. Since bonding to such a smooth surface produces less interlocking, there are increasing concerns about decreased bonding strength and durability of allceramic crowns ${ }^{14-16}$, even if resin cement is applied. The Rocatec system has been reported to be useful for ceramics, with the combination of a silane coupling agent ${ }^{17,18}$. However, the effect of the system on glass ceramics $^{19)}$ for CAD/CAM use, and the application of a functional monomer as a primer have not yet been evaluated.

Therefore, in this study, we investigated the effects of the following on bond strength of leucite-reinforced glass ceramics for CAD/CAM use with a resin cement: surface modification by tribochemical (TBC) treatment, followed by combined application of a silane coupling agent and a functional monomer as a primer.

\section{MATERIALS AND METHODS}

\section{Shear bond test}

1. Experimental materials

Table 1 lists the materials used in this study: a ceramic block, particles for sandblasting, TBC treatment for surface modification, a silane coupling agent and a functional monomer as a primer, and a resin cement for luting. For bonding surfaces, plate specimens $(10 \times 12 \times 2 \mathrm{~mm})$ were cut from the ceramic block using a low-speed diamond cutting saw (Isomet, Buehler). Additionally, the specimens were subjected to ultrasonic cleaning for 15 minutes in an acetone solution, followed by heat treatment according to the manufacturer's instructions $\left(780^{\circ} \mathrm{C}\right.$ for two minutes) to simulate the routine staining procedures in a laboratory. Specimens were then stored for 24 hours in a desiccator at room temperature before being used as bonding surfaces in this study.

2. Surface modification

2.1 Non-modified surface

The abovementioned heat-treated, flat ceramic specimens were used as they were as bonding surfaces. They served as non-modified (NM) 
Table 1 Materials used in this study

\begin{tabular}{|c|c|c|c|c|c|}
\hline Material & Application & Code & Product Name & Batch No. & Manufacturer \\
\hline Leucite reinforced & $\begin{array}{l}\mathrm{CAD} / \mathrm{CAM} \text { milling } \\
\text { glass ceramics }\end{array}$ & LRG & ProCAD & & Ivoclar Vivadent \\
\hline $\begin{array}{l}\text { Silica-coated alumina } \\
\text { (Average particle size, } 30 \mu \mathrm{m} \text { ) }\end{array}$ & $\begin{array}{l}\text { Surface modification } \\
\text { (Tribochemical treatment) }\end{array}$ & SA & Rocatec soft & 178108 & 3M ESPE \\
\hline $\begin{array}{l}\text { a -alumina } \\
\text { (Average particle size, } 25 \mu \mathrm{m} \text { ) }\end{array}$ & $\begin{array}{l}\text { Surface modification } \\
\text { (Sandblast treatment) }\end{array}$ & $\mathrm{AL}$ & WA25 & 9E0710 & Heraeus kulzer \\
\hline Silane coupling agent & Primer treatment & $\mathrm{SC}$ & Espesil & 207948 & 3M ESPE \\
\hline Functional monomer & Primer treatment & $\mathrm{FM}$ & Epricord opaque primer & 0133AA & Kuraray Medical \\
\hline Resin-based cement & Luting & $\mathrm{RC}$ & RelyX ARC (Shade:A3) & FAFJ & 3M ESPE \\
\hline
\end{tabular}

surfaces.

2.2 Blasting with alumina particles

Using a sandblast treatment device (Rocatec Junior, 3M ESPE), alumina powder with a mean particle size of $25 \mu \mathrm{m}$ was blasted onto the bonding surface of ceramic specimens, at a pressure of $0.28 \mathrm{MPa}$ $\left(13 \mathrm{~s} / \mathrm{cm}^{2}\right)$ and at a distance of $10 \mathrm{~mm}$ from the bonding surface. After which, compressed air was used to remove powder from the bonding surface. This bonding surface served as a sandblast-treated surface (BAL).

2.3 Blasting with silica-coated alumina particles

Using a TBC treatment device (Rocatec Junior, 3M ESPE), silica-coated alumina particles with a mean particle size of $30 \mu \mathrm{m}$ (Rocatec Soft, 3M ESPE) were blasted onto the bonding surfaces of ceramic specimens, at a pressure of $0.28 \mathrm{MPa}\left(13 \mathrm{~s} / \mathrm{cm}^{2}\right)$ and at a distance of $10 \mathrm{~mm}$ from the bonding surface, as recommended by the manufacturer. After which, compressed air was used to remove powder from the modified surface. This bonding surface served as a TBC-treated surface (BSA).

3. Primer treatments

3.1 Non-primer treatment

Specimens not subjected to either of the following two types of primer application served as nonprimer-treated (NP) surfaces.

3.2 Treatment with a silane coupling agent

A silane coupling agent was applied to the bonding surface, as recommended for the Rocatec system. After application, the silane coupling agent was left to stand for five minutes according to the manufacturer's instructions, and then dried. This served as a silane coupling-treated (SCT) surface.

3.3 Treatment with a functional monomer

An adhesive primer containing the functional monomer of 10-methacryloyloxydecyl dihydrogen phosphate (MDP) was applied to the bonding surface.
Table 2 Surface modification and primer treatment conditions of ceramic specimens

\begin{tabular}{llll}
\hline Surface modification & Code & Primer treatment & Code \\
\hline No modification & NM & No primer & NP \\
$\begin{array}{l}\text { Blasting with alumina } \\
\text { particles }\end{array}$ & BAL & Functional monomer & FMT \\
$\begin{array}{l}\text { Blasting with silica-coated } \\
\text { alumina particles }\end{array}$ & BSA & Silane coupling agent & SCT \\
& & $\begin{array}{l}\text { Combinations of silane } \\
\text { coupling agent and } \\
\text { functional monomer }\end{array}$ &
\end{tabular}

After application, the adhesive primer was left to stand for three minutes, and then dried. This served as a functional monomer-treated (FMT) surface.

4. Treatment conditions for the bonding surface Table 2 summarizes the surface modification and primer treatment conditions of the bonding surfaces of ceramic specimens. A total of 12 types of bonding surface treatments were prepared, consisting of three types of modified surfaces as mentioned above and four types of primer treatment.

5. Preparation of shear bond test specimens

5.1 Ceramic bonding surface

To prevent deformation due to polymerization contraction of resin cement, $80-\mu \mathrm{m}$-thick double-sided tape (Sekisui Tape) with a hole $8 \mathrm{~mm}$ in diameter was affixed to a glass plate. An acrylic tube with an inner diameter of $16 \mathrm{~mm}$ was adhered to the glass plate with this hole of the tape in the center. A ceramic test specimen was placed in this acrylic tube and tightly fixed, so that the bonding surface was on the bottom. After which, cold-curing resin (Palapress Vario, Heraeus Kulzer) was poured into 
the acrylic tube to invest the ceramic test specimen. After resin hardening, the acrylic tube with ceramic specimen was removed from the glass plate. Fiftymicrometer-thick vinyl tape with a hole $6 \mathrm{~mm}$ in diameter (Vinyl Patches, Kokuyo) was affixed to the bonding surface of the ceramic test specimen to define the bonding area.

5.2 Titanium bonding body

For the bonding body test specimens, JIS grade 2 titanium rod (KS-50, Kobelco), with a diameter of 8 $\mathrm{mm}$, was cut using a low-speed diamond saw (Isomet, Buehler) to prepare 180 titanium disk specimens $(8 \times$ $2 \mathrm{~mm}$ ). Using a sandblasting device (Combilabor CLFSG 3, Heraeus Kulzer), alumina powder with a mean particle size of $250 \mu \mathrm{m}$ was blasted at a pressure of $0.45 \mathrm{MPa}\left(13 \mathrm{~s} / \mathrm{cm}^{2}\right)$ and at a distance of $10 \mathrm{~mm}$ onto the bonding surfaces of titanium disk specimens. Then, the specimens underwent ultrasonic cleaning for 15 minutes in an acetone solution. Titanium is known to have excellent bonding to resin cement when an adhesive primer containing the functional monomer of methacryloyloxydecyl dihydrogen phosphate (MDP) is used ${ }^{20,21}$. As such, a metal adhesive primer containing MDP was applied to the bonding surface of titanium.

5.3 Bonding procedure

The bonding surfaces of ceramic specimens - subjected to respective surface treatments - and titanium bonding bodies were bonded with a resin cement. Cement paste mixed at a powder-liquid ratio recommended by the manufacturer was applied to the ceramic bonding surface in the area defined by the tape, and then pressed onto the titanium bonding body specimen. Bonded pieces were immediately subjected to a fixed load of $2 \mathrm{kgf}$, and excess cement paste was removed. Since the resin cement used in this study was a dual-cure cement, the area around the bonding surface was lit with a light curing unit (Optilux 400, Demetron) from four directions for 20 seconds. Once hardening was complete, specimens were immersed in $37^{\circ} \mathrm{C}$ deionized water and stored for 24 hours. In addition, bonded test specimens were subjected to 20,000 cycles of thermal stress durability test, with immersion in 5 and $60^{\circ} \mathrm{C}$ deionized water for one minute.

6. Shear bond test

A universal testing machine (1125-5500R, Instron) was used for the shear bond test, as illustrated in Fig. 1. Shear bond test was performed at a crosshead speed of $1.0 \mathrm{~mm} / \mathrm{min}$. Shear bond strength was defined as the bonding area divided by the fracture load, and which served as a bonding evaluation parameter for each surface treatment. Using one-way ANOVA and Tukey's multiple comparison test, SBS values obtained were statistically analyzed $(p<0.05)$ for each surface modification and primer treatment.

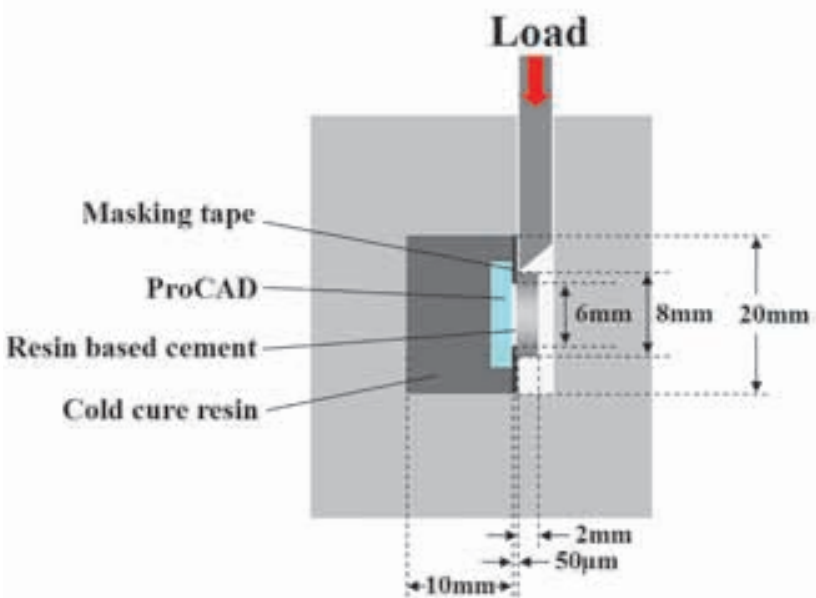

Fig. 1 Schematic illustration of the testing device for shear bond test.

\section{Elemental analysis}

To examine compositional changes in the bonding surface after blasting with alumina and silica-coated alumina particles, oxides on the bonding surface were analyzed quantitatively at an acceleration voltage of $50 \mathrm{kV}$ and a current of $30 \mathrm{~mA}$, under a reduced pressure of $30 \mathrm{~Pa}$, using an X-ray fluorescence spectrometer (EDX-700, Shimadzu). In particular, we evaluated the compositional changes in the quantity of silica and alumina present in the bonding surface. Obtained data were statistically analyzed for each surface blasted with alumina and silica-coated alumina, using one-way ANOVA and Tukey's multiple comparison test $(\mathrm{p}<0.05)$.

\section{SEM observation of fractured surfaces}

The surfaces of ceramic specimens with and without surface modification before bonding were observed using a scanning electron microscope (SEM; S2360N, Hitachi), after sputtering with platinum-palladium alloy. After the shear bond test, the fractured surfaces of BSA, modified with several primer treatments, were also observed. In addition, failure after the shear bond strength test was also evaluated as cohesive or adhesive.

\section{RESULTS}

\section{Shear bond strength (SBS)}

As shown in Fig. 2, primer treatment affected the shear bond strength for all surface modification conditions. Specimens with an NM surface had a marked increase in bond strength $(\mathrm{p}<0.05)$ for specimens that underwent primer treatments (FMT, SCT, $\mathrm{COM}$ ) over non-primer treatment (NP). The shear bond strength of these NM surfaces increased in the order of NP, FMT, SCT, and COM. However, there 
was no significant difference between FMT and SCT $(p>0.05)$. On the other hand, COM - that is, combined FMT and SCT - had a significantly higher SBS $(p<0.05)$ than either primer treatment alone.

The shear bond strength of sandblast-treated surfaces (BAL) increased in the order of NP, FMT, $\mathrm{SCT}$, and COM. There were no significant differences between NP and FMT and between FMT and SCT $(p>0.05)$; although only COM had a significantly higher shear bond strength $(p<0.05)$ than other treatments.

Similarly, the shear bond strength of tribochemical-treated surfaces (BSA) increased in the order of NP, FMT, SCT, and COM. With SCT, shear bond strength was significantly higher $(p<0.05)$ than that with FMT. With COM, shear bond strength was significantly higher $(\mathrm{p}<0.05)$ than that with SCT. It was noteworthy that with COM, shear bond strength was the highest at $52 \mathrm{MPa}$ in this study.

Table 3 shows the shear bond strengths of ceramic specimens subjected to different surface modifications and after 20,000 thermal cycles. Surface modification affected the shear bond strength for each primer treatment condition. Indeed, as a result of surface modification, a statistically significant $(p<0.05)$ increase in shear bond strength was noted, when compared to that with primer treatment. However, with FMT, no statistically significant differences were noted among any of the surface modification treatments $(\mathrm{p}>0.05)$. With $\mathrm{SCT}$, shear bond strength increased in the order of NM, BAL, and BSA - and the differences were statistically significant $(p<0.05)$. With COM, there was a significant difference $(p<0.05)$ in shear bond strength between BAL and BSA - which was a contrast to NP.

After thermal cycling, shear bond strength increased in the order of NT, FMT, SCT, and COM. There were no significant differences between NP and FMT, and between FMT and SCT ( $p>0.05)$.

\section{Elemental analysis}

Figure 3 shows the oxide elements in NM, BAL, and BSA surfaces of ceramic specimens, as analyzed by X-ray fluorescence (XRF) spectroscopy. The relative composition of ceramic specimens was as follows: $\mathrm{SiO}_{2}, 50.4 \%$; $\mathrm{Al}_{2} \mathrm{O}_{3}, 20 \% ; \mathrm{K}_{2} \mathrm{O}, 15 \%$; and $\mathrm{CaO}$, $10 \%$. After BSA treatment, the composition of $\mathrm{SiO}_{2}$ rose to $53.8 \%$, thereby registering a significant increase $(\mathrm{p}<0.05)$. On the other hand, $\mathrm{Na}_{2} \mathrm{O}$ decreased slightly and $\mathrm{Al}_{2} \mathrm{O}_{3}$ remained almost unchanged.

\section{SEM observations}

From the SEM observation of the fractured surfaces, no adhesive fractures occurred at the interface with the titanium body. Every fracture occurred at either

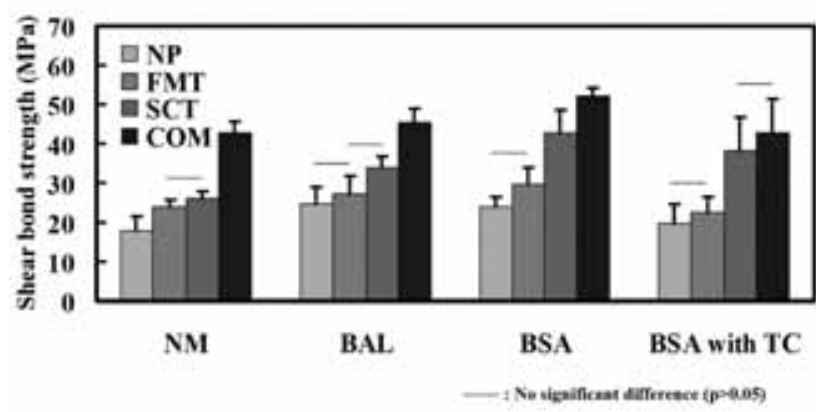

Fig. 2 SBS values of resin-based cement applied to LRG ceramics - subjected to several primer treatments — to each modified surface. *: No significant differences $(p>0.05)$.

Table 3 SBS values of resin-based cement to leucitereinforced silicate glass (LRG) ceramics subjected to several surface and primer treatment methods. Mean values with same superscript letters among NM, BAL, and BSA of each primer treatment, and vertical lines between BSA and BSA with thermal cycling $(20,000)$ indicate no statistically significant differences $(\mathrm{p}>0.05)$

\begin{tabular}{|c|c|c|c|c|}
\hline Tr eatment ( ${ }_{\text {Sur faœ }}$ Primer & ) $N P$ & $\mathrm{FMT}$ & SCT & $\mathrm{COM}$ \\
\hline \multirow[t]{2}{*}{$\mathrm{NM}$} & 17.7 & $23.8^{\mathrm{b}}$ & 26.1 & $42.8^{c}$ \\
\hline & (3.7) & (19) & (18) & $(3.0)$ \\
\hline \multirow[t]{2}{*}{ BA L } & $24.6^{a}$ & $27.2^{\mathrm{b}}$ & 33.8 & $45.5^{\mathrm{c}}$ \\
\hline & $(4.2)$ & (4.6) & (29) & $(3.4)$ \\
\hline \multirow[t]{2}{*}{ BSA } & $23.9^{a}$ & $29.6^{\mathrm{b}}$ & 43.0 & 52.2 \\
\hline & (26) & $(4.2)$ & $(5.7)$ & $(2.1)$ \\
\hline \multirow[t]{2}{*}{ BSA with TC } & 18.3 & 22.6 & 38.3 & 43.0 \\
\hline & (4.1) & (3.9) & (8.5) & $(8.5)$ \\
\hline
\end{tabular}

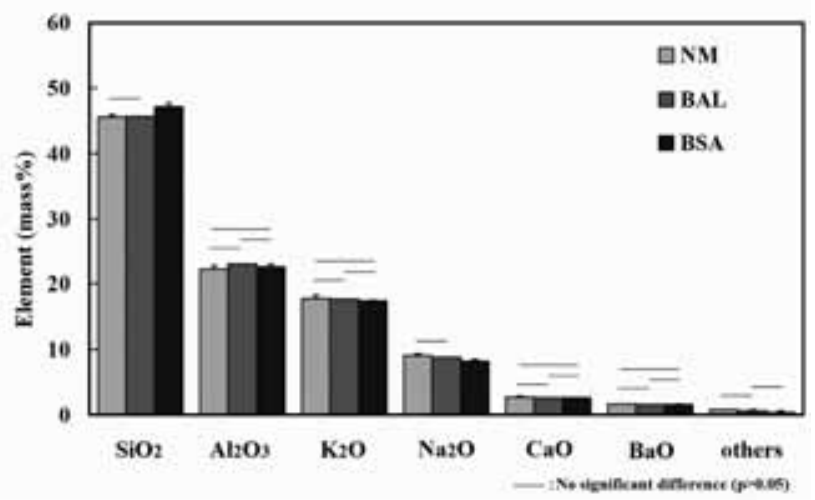

Fig. 3 Oxides in LRG ceramics with no modification $(\mathrm{NM})$, and after treatment with BAL and BSA, as analyzed by XRF. *: No significant differences $(p>0.05)$. 
$\square$ cohesive $\square$ adhesive

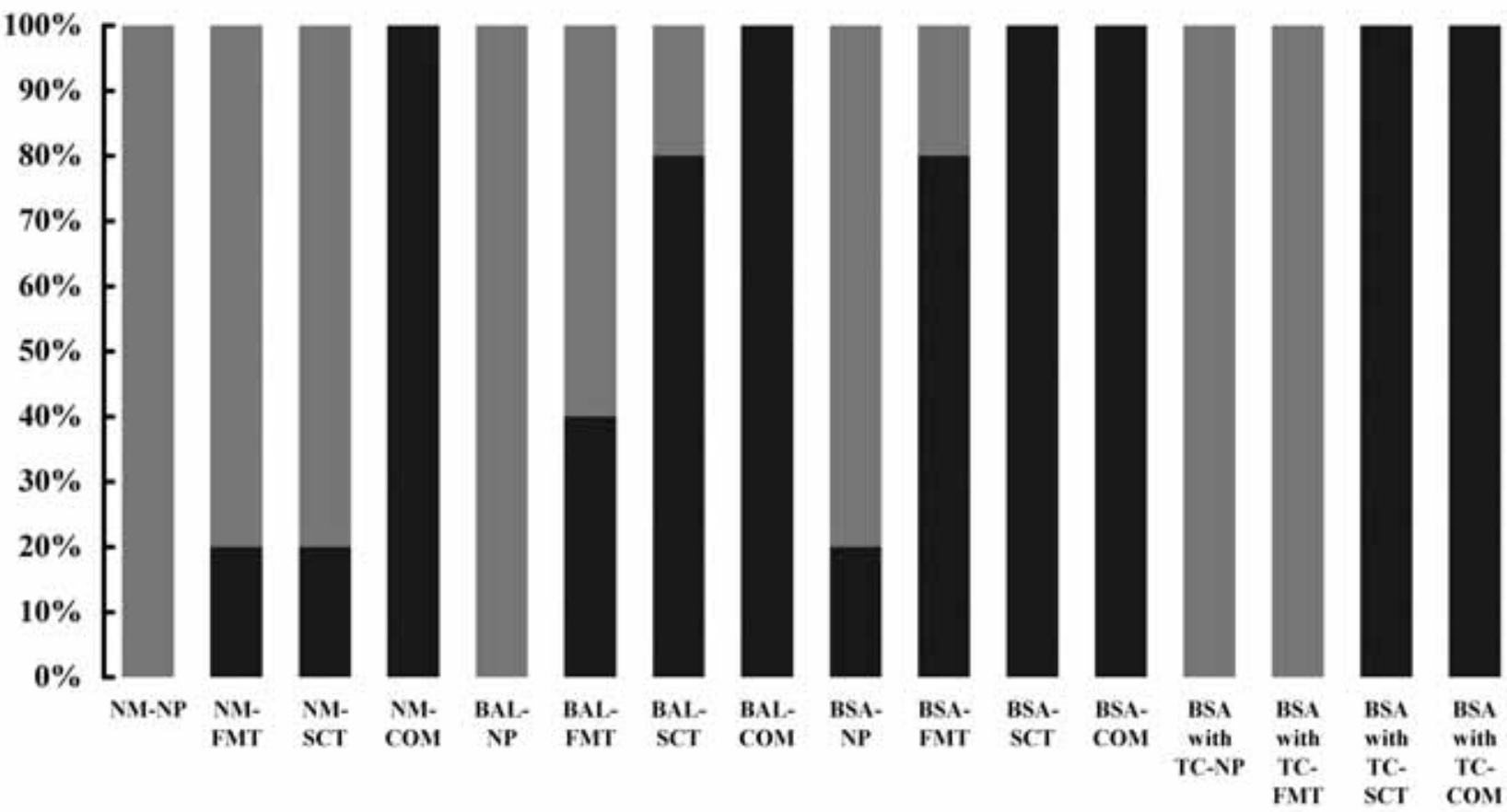

Fig. 4 Ratios of fracture modes between ceramics and cement.

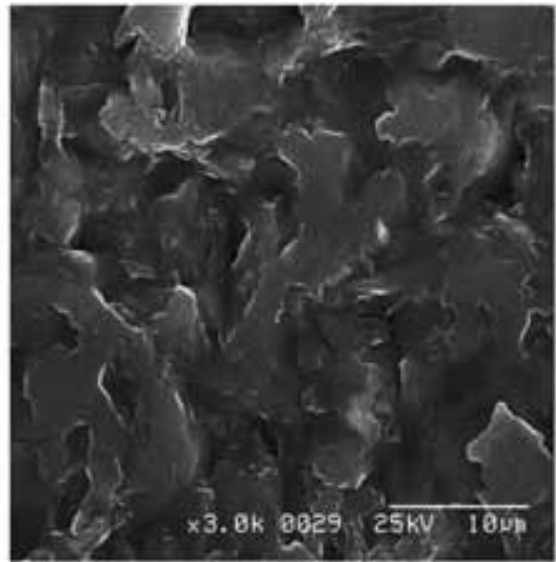

NM

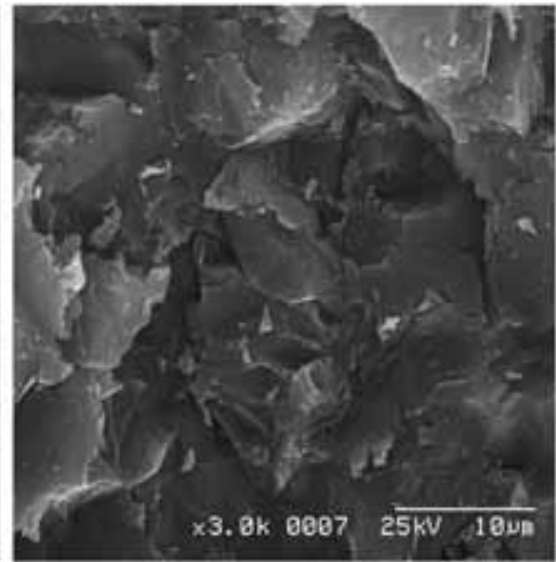

BAL

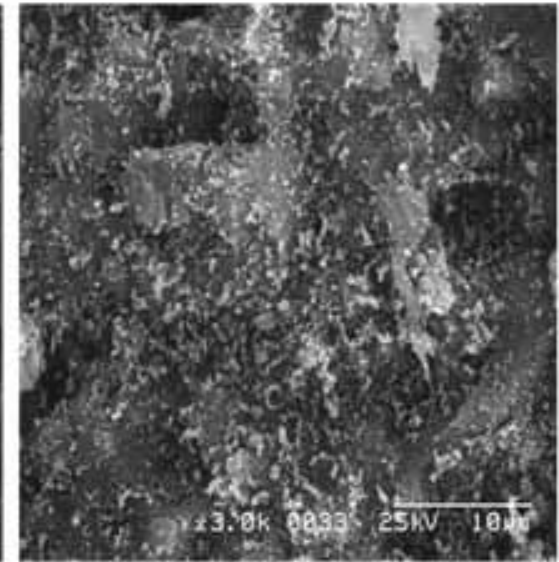

BSA

Fig. 5 SEM images of LRG ceramic surfaces before (NM) and after modification (BAL, BSA).

the interface between the ceramic surface and cement (adhesive mode) or within the cement (cohesive mode) (Fig. 4).

Figure 5 shows the SEM images of ceramic specimens following each surface modification. With the NM surface, a number of rounded pits and bumps were observed. Following BAL treatment, the degree of roughness decreased but a number of sharp pits and bumps was observed, as with the NM surface. With the BSA surface, a layer of fine particles was attached on a rough, uneven surface, similar to that of BAL surface.

Figure 6 shows the SEM images of the fractured surfaces after shear bond testing. Fractured NM surface appeared like the pre-bonding state, and interfacial fracture was apparent. For fractured FMT surface, a mixed failure occurred and the resin component remained in the pits. For the fractured SCT and COM surfaces, cohesive failure occurred and the surface was completely covered with resin-based cement. 


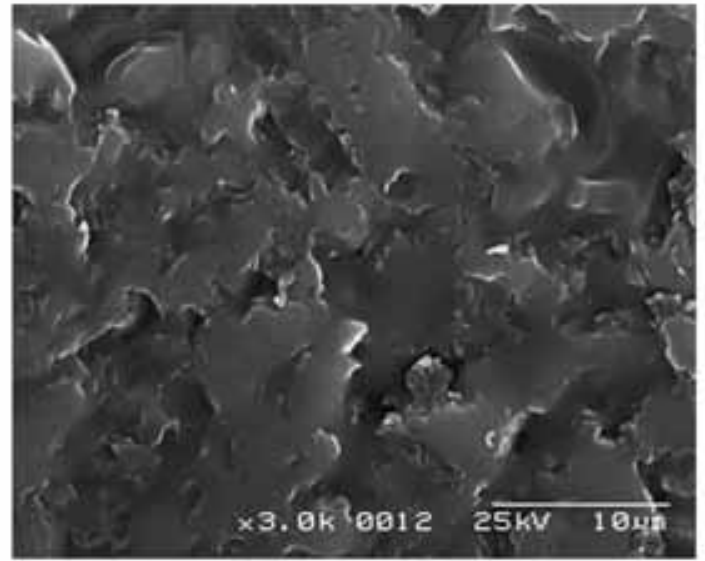

NM

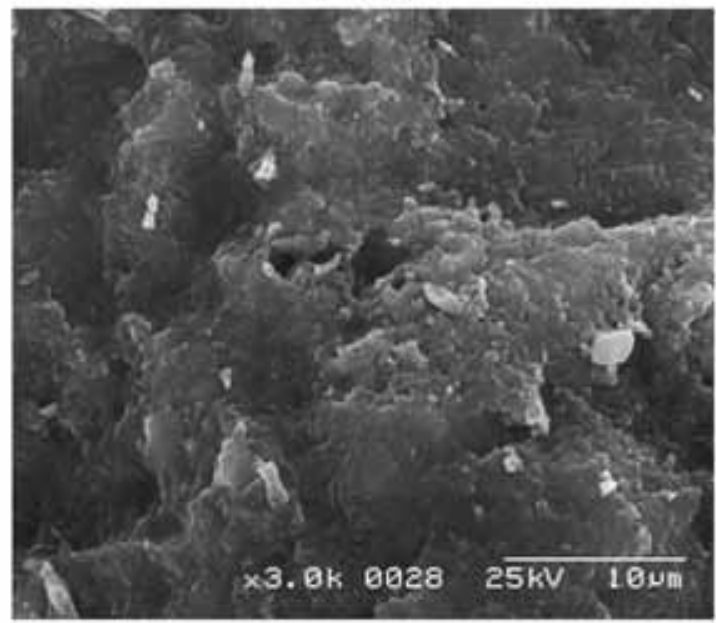

SCT

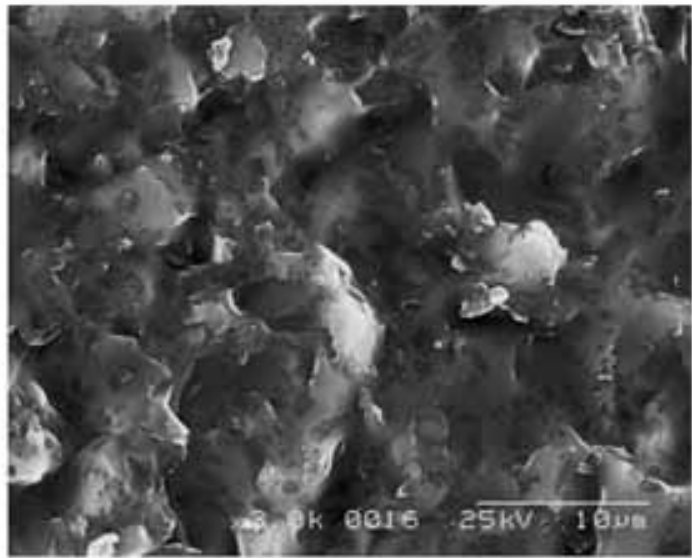

FMT

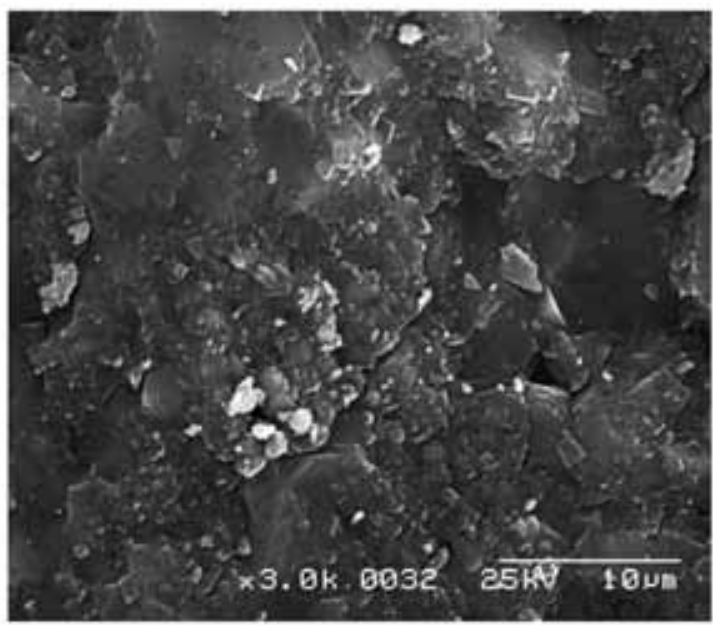

$\mathrm{COM}$

Fig. 6 SEM images of the fractured surfaces of LRG ceramics modified with BSA and then applied with each primer treatment, after shear bond test.

\section{DISCUSSION}

In dentistry, surface treatment is a means currently used to increase the bonding of luting resin cements to substrates. Presently available surface treatment methods either employ sandblasting or utilize chemical bonding. With sandblasting, the objective is to change the surface topography, increase the bonding area, and expose an active surface. In the case of chemical bonding, a silane coupling agent and a functional monomer are typically applied to improve bonding ${ }^{22,23}$.

Sandblasting of ceramics is not performed conventionally because it may produce poor marginal compatibility due to chipping and micro-cracks. However, since the internal surface of $\mathrm{CAD} / \mathrm{CAM}$ fabricated crowns is relatively smooth, it might be expedient to increase the bonding area with due consideration to the treatment conditions used in this study. BAL and BSA surfaces, as observed by SEM (Fig. 5), increased the bonding area by roughening the surface and thereby increasing the bond strength (Table 3).

The Rocatec system has been reported to be an effective surface treatment method for ceramics, regardless of the bonding material chosen. This is because it combines TBC treatment with a silane coupling agent ${ }^{24,25}$. When it first emerged in the market, it entailed two steps of blasting treatment: sandblasting with alumina powder, followed by intermixing with silica particles. In this manner, a silica layer was produced as a surface layer on the bonding surface ${ }^{26)}$.

Recently, however, this treatment method is reduced to only one step: sandblasting with silicacoated alumina powder, whereby silica coating is performed using friction chemistry. It should be noted though that a metal surface layer sandblasted with alumina powder is known to have a large 
amount of residual alumina powder. Therefore, in this study, although TBC treatment was carried out at a lower pressure $(0.28 \mathrm{MPa})$ than for ordinary blasting, surface contamination by alumina powder was assumed to occur on the ceramic surface due to blasting with silica-coated alumina.

Based on the elemental analysis of the alumina-sandblasted surfaces, no marked changes in alumina were observed. Besides, there was no clear intrusion of alumina particles into the sandblasted surface, as observed by SEM. Although the blasted surface was somewhat more rounded than the fired surface before blasting - which served as a control, there were no substantial differences in surface features. This was because silica-based ceramics are harder than metals.

Moreover, ceramics are brittle materials with minimal allowance for plastic deformation. Therefore, sandblasting has an attenuated effect on ceramics, thus causing less contamination by alumina. With the TBC-treated surface in this study, an increase in silica quantity by $\sim 3 \%$ was observed. SEM image of the TBC-treated surface also differed from that of sandblasted surface: a large amount of fine powder was observed to be bind to the rough surface. This powder was markedly finer than alumina powder. Therefore, it was suggested to be silica, by virtue of the silica layer created by blasting.

With the BSA method, silica is left in the surface layer. TBC treatment conveys the mechanical energy of sandblasting to the treated surface in the form of kinetic energy, and chemical bonds are produced by this energy. Silication broadly occurs without producing a rise in temperature, and its effects are influenced at the atomic and molecular levels. Silane coupling agents react with the residual silica layer, and a siloxane network is formed by hydrolysis and crosslinking. Thus, Rocatec treatment using a TBC method has been reported to provide good bonding with durability for dental materials, such as metals, resins, and ceramics ${ }^{27-29)}$. In this experiment, the BSA surface (Fig. 2) displayed marked improvement in bond strength when treated with the silane coupling agent, as compared with the functional monomer. Therefore, the BSA method was also an effective surface modification method for ceramics.

A silane coupling agent is typically used as a surface treatment agent for dental ceramics. The silane coupling agent used is mainly $\mathrm{Y}$-methacryloxy propyltrimethoxysilane ( $\mathrm{Y}-\mathrm{MPTS}$ ), which has three methoxy groups bonded to silicon inside the molecule. Thus, it specifically attaches to the bonding surface silicon, and a siloxane network consisting of covalent bonds is formed by dehydration and condensation. This is known to produce a strong bond with silica ${ }^{30-34)}$.

For all modified ceramic surfaces used in this study, silane coupling treatment significantly increased the bond strength. In particular, a marked increase was noted for the TBC surface. On this account, this surface treatment method was confirmed to be effective for improving the bond strength of leucite-reinforced silica-based glass ceramics. With these ceramic surfaces, the silane coupling agent acted on $\mathrm{SiO}_{2}$ - their principal component at $59-63 \%$, and $\mathrm{Y}$-MPTS and silicone groups were presumed to have formed siloxane bonds.

Another surface treatment method used in this study was primer treatment using MDP as a functional monomer. Functional monomers are used primarily for bonding with teeth and non-precious metals. They have been reported to substantially improve bonding, but they are not appropriate for ordinary ceramics. In this study, the bond strength of FMT to an unmodified surface increased slightly, but no significant differences were observed - except for the NM surface. It should be mentioned that functional monomers might have improved the wetting of resin cement on the surface of ceramic specimens.

Leucite-reinforced silicate glass used in this study contained abundant silica as their principal component. However, many oxides were also added, thereby limiting its enhanced bonding capability with primer treatment using a silane coupling agent. It should be put into perspective that complete bonding for all the elements cannot be achieved with one surface treatment method alone. Thus, in this study, a combination surface treatment (COM) was attempted to provide further improvement in adhesiveness by combining surface modification and surface treatment.

Interestingly, when the combination surface treatment of silane coupling agent and functional monomer was performed for the same modified surface, bond strength was significantly higher than those of untreated surface, FMT surface, and SCT surface (Fig. 2).

From the data of Table 3, the bond strengths of NP-NM and NP-BSA with TC were apparently lower than the others. Nonetheless, these bond strengths were sufficient to ensure good clinical service. This is because a value limit of $10-13 \mathrm{MPa}$ is suggested as the minimum for acceptable long-term, clinical bonding $^{35)}$.

Moreover, as shown in Fig. 3, COM primer treatment on BSA surface produced the highest shear bond strength of $52 \mathrm{MPa}$, and there was only a slight reduction in bond strength following thermal cycling. In other words, bond durability was also excellent.

Silane coupling treatment in dentistry produces 
siloxane bonds between hydroxyl and methoxy groups on the ceramic surface. Therefore, $\mathrm{y}$-MPTS must be activated to promote the hydrolysis of methoxy groups on the ceramic surface. Dental silane coupling treatment activates $\mathrm{Y}$-MPTS by creating a generally acidic environment ${ }^{36)}$. In this study, MDP was used an acidic monomer, as is used in primers for dentin bonding. The composition of a conventional silane coupling agent features, besides the coupling agent itself, ethanol in solution and water for hydrolysis. However, the silane coupling agent used in this study was specific for the Rocatec system and did not contain water. Nonetheless, moisture in the air might be absorbed following ceramic surface coating when left to stand for five minutes longer than ordinary dental ceramic primers, thereby promoting hydrolysis of $\mathrm{Y}$-MPTS. MDP monomer applied for the second time dissociated and produced an acidic environment, reactivating the silane coupling agent. At the same time, acetone in the functional monomer activated the condensation reaction of the silane coupling agent. When these events multiplied, it then resulted in markedly increased bond strength for the combination surface treatment used in this study.

Based on the results of this study, it could be said that when a surface treatment agent, such as a silane coupling agent, was combined with surface modification by TBC treatment, it led to markedly improved adhesiveness of dental ceramics. For future expansion upon the current study, the treatment conditions will be further examined in detail with a view to arriving at the appropriate and optimal conditions.

\section{CONCLUSIONS}

Within the limitations of the present study, the following conclusions were drawn:

1. Tribochemical treatment slightly roughened the ceramic surface and surface activation improved bond strength.

2. With the application of a silane coupling agent, the bond strength yielded was greater than that with a functional monomer. While application of a silane coupling agent was useful for all the surfaces tested, it was particularly so for the tribochemical-treated surface.

3. Combination of a silane coupling agent and a functional monomer as a primer on the tribochemical-treated surface markedly improved bonding. Durability was also good after thermal cycling. Therefore, it was suggested that tribochemical treatment followed by application of silane coupling agent and functional monomer substantially increased the bond strength of CAD/CAM-fabricated glass ceramics with resin cement, if the treatment conditions were appropriate.

\section{ACKNOWLEDGEMENTS}

We gratefully acknowledge the assistance rendered by members of the department of prosthodontics and department of oral biomaterials and technology, Showa university school of dentistry, Japan. This work was partially supported by a Grant-in-aid for Scientific Research, C(2) No. 18592144, from the Ministry of Education, Culture, Sports, Science and Technology of Japan.

\section{REFERENCES}

1) Hegenbarth EA. Procera aluminum oxide ceramics: a new way to achieve stability, precision and esthetics in all-ceramic restorations. Quintessence Dent Technol 1996; 19: 21-34

2) Mormann WH, Bindl A, Luthy H, Rathke A. Effect of preparation and luting system on all-ceramic computer-generated crowns. Int J Prosthodont 1998; 11: 333-339.

3) Tinschert J, Zwez D, Marx R, Anusavice KJ. Structural reliability of alumina-, feldspar-, leucite-, mica- and zirconia-based ceramics. J Dent 2000; 28: 529-535.

4) Raigrodski AJ. Contemporary materials and technologies for all-ceramic fixed partial dentures: A review of the literature. J Prosthet Dent 2004; 92: 557-562.

5) Nakamura T, Dei N, Kojima T, Wakabayashi K. Marginal and internal fit Cerec $3 \mathrm{CAD} / \mathrm{CAM}$ allceramic crowns. Int J Prosthodont 2003; 16: 244-248.

6) Hotta Y, Miyazaki T, Fujiwara T, Tomita S, Shinya A, Sugai Y, Ogura H. Durability of tungsten carbide burs for the fabrication of titanium crowns using dental CAD/CAM. Dent Mater J 2004; 23: 190-196.

7) Tomita S, Shinya A, Gomi H, Matsuda T, Katagiri S, Shinya A, Suzuki H, Yara A, Ogura H, Hotta Y, Miyazaki T, Sakamoto Y. Machining accuracy of CAD/CAM ceramic crowns fabricated with repeated machining using the same diamond bur. Dent Mater J 2005; 24: 123-133.

8) Nakamura T, Tanaka H, Kinuta S, Akao T, Okamoto $\mathrm{K}$, Wakabayashi $\mathrm{K}$, Yatani $\mathrm{H}$. In vitro study on marginal and internal fit of $\mathrm{CAD} / \mathrm{CAM}$ all-ceramic crowns. Dent Mater J 2005; 24: 456-459.

9) Bindl A, Lüthy H, Mörmann WH. Strength and fracture pattern of monolithic CAD/CAM-generated posterior crowns. Dent Mater 2006; 22: 29-36.

10) Mota CS, Demarco FF, Camacho GB, Powers JM. Tensile bond strength of four resin luting agents bonded to bovine enamel and dentin. J Prosthet Dent 2003; 89: 558-564.

11) Kim JY, Preiffer P, Niedermeier W. Effect of laboratory procedures and thermocycling on the shear bond strength of resin-metal bonding system. J Prosthet Dent 2003; 90: 184-189.

12) Komine F, Tomic M, Gerds T, Strub JR. Influence of different adhesive resin cements on the fracture strength of aluminum oxide ceramic posterior crowns. 
J Prosthet Dent 2004; 92: 359-364.

13) Shimada Y, Yamaguchi S, Tagami J. Micro-shear bond strength of dual-cured resin cement to glass ceramics. Dent Mater 2002; 18: 380-388.

14) El Zohairy AA, De Gee AJ, Mohsen MM, Feilzer AJ. Microtensile bond strength testing of luting cements to prefabricated CAD/CAM ceramic and composite blocks. Dent Mater 2003; 19: 575-583.

15) Della Bona A, Anusavice KJ, Mecholsky Jr JJ. Failure analysis of resin composite bonded to ceramic. Dent Mater 2003; 19: 693-699.

16) Attia A, Kern M. Fracture strength of all-ceramic crowns luted using two bonding methods. J Prosthet Dent 2004; 91: 247-252.

17) Blixt M, Adamczak E, Linden LA, Oden A, Arvidson K. Bonding to densely sintered alumina surfaces: Effect of sandblasting and silica coating on shear bond strength of luting cements. Int $\mathrm{J}$ Prosthodont 2000; 13: 221-226.

18) Janda R, Roulet JF, Wulf M, Tiller HJ. A new adhesive technology for all-ceramics. Dent Mater 2003; 19: 567-573.

19) Chen HY, Hickel R, Setcos JC, Kunzelmann KH. Effects of surface finish and fatigue testing on the fracture strength of $\mathrm{CAD} / \mathrm{CAM}$ and pressed-ceramic crowns. J Prosthet Dent 1999; 82: 468-475.

20) Taira Y, Matsumura H, Yoshida K, Tanaka T, Atsuta M. Adhesive bonding of titanium with a methacrylate phosphate primer and self-curing adhesive resins. J Oral Rehabil 1995; 22: 409-412.

21) Matsumura $H$, Yoshida $K$, Tanaka T, Atsuta M. Adhesive bonding of titanium with a titanate coupler and 4-META/MMA-TBB opaque resin. J Dent Res 1990; 69: 1614-1616.

22) Takahashi H. Clinical evaluation of silane coupling agent. J Dental Medicine 1987; 25: 26-36.

23) Hooshmand T, Van Noort R, Keshvad A. Bond durability of the resin-bonded and silane treated ceramic surface. Dent Mater 2002; 18: 179-188.

24) Robin C, Scherrer SS, Wiskott HWA, de Rijk WG, Belser UC. Weibull parameters of composite resin bond strengths to porcelain and noble alloy using the Rocatec system. Dent Mater 2002; 18: 389-395.

25) Gzcan M, Vallittu PK. Effect of surface conditioning methods on the bond strength of luting cement to ceramics. Dent Mater 2003; 19: 725-731.

26) Kern M, Thompson VP. Sandblasting and silicacoating of dental alloys : volume loss, morphology and changes in the surface composition. Dent Mater 1993; 9: $155-161$.

27) Kern M, Wegner SM. Bonding to zirconia ceramic: adhesion methods and their durability. Dent Mater 1998; 14: 64-71.

28) Hummel M, Kern M. Durability of the resin bond strength to the alumina ceramic Procera. Dent Mater 2004; 20: 498-508.

29) Amaral R, Özcan M, Bottino MA, Valandro LF. Microtensile bond strength of a resin cement to glass infiltrated zirconia-reinforced ceramic: The effect of surface conditioning. Dent Mater 2006; 22: 283-290.

30) Hayakawa T, Horie K, Aida M, Kanaya T, Kobayashi $\mathrm{T}$, Murata Y. The influence of surface condition and silane agent on the bond of resin to dental porcelain. Dent Mater 1992; 8: 238-240.

31) Suliman AHA, Swift EJ, Perdigao J. Effects of surface treatment and bonding agents on bond strength of composite resin to porcelain. J Prosthet Dent 1993; 70: 118-120.

32) Yoshida K, Kamada K, Atsuta M. Effect of two silane coupling agents, a bonding agent, and thermal cycling on the bond strength of a CAD/CAM composite material cemented with two resin luting agents. J Prosthet Dent 2001; 85: 184-189.

33) Foxton RM, Nakajima M, Hiraishi N, Kitasako Y, Tagami J, Nomura S, Miura H. Relationship between ceramic primer and ceramic surface $\mathrm{pH}$ on the bonding of dual-cure resin cement to ceramic. Dent Mater 2003; 19: 779-789.

34) C̈zcan M, Matinlinna JP, Vallittu PK, Huysmans MC. Effect of drying time of 3-methacryloxypropyltrimethoxysilane on the shear bond strength of a composite resin to silica-coated base/noble alloys. Dent Mater 2004; 20: 586-590.

35) Thurmond J, Barkmeier W, Wildwerding M. Effect of porcelain surface treatments on bond strengths of composite resin bonded to porcelain. J Prosthet Dent 1994; 72: 355-359.

36) Kadoma Y. Surface treatment agent for dental metals using a thiirane monomer and a phosphoric acid monomer. Dent Mater J 2002; 21: 156-169. 